\title{
An account of 335 cases of megaloblastic anaemia of pregnancy and the puerperium
}

\author{
C. GILES
}

From the City General Hospital, Stoke-on-Trent

SYNOPSIS The incidence of megaloblastic anaemia in pregnancy and the puerperium in north Staffordshire has steadily declined as a result of prophylaxis with folic acid. In the presence of advanced folic acid deficiency and with a florid megaloblastic marrow, the anaemia is usually severe, but in many patients the disease is relatively mild and the degree of anaemia is determined more by blood loss or associated iron deficiency than by the megaloblastosis.

Microscopic examination of marrow films is still the most reliable method of diagnosis, although estimation of the labile serum folate has produced a $95 \%$ correlation with the marrow findings.

There are three main factors which operate in the pathogenesis of megaloblastic anaemia in pregnancy and the puerperium. First, the maternal stores of folic acid are used up by the growing foetus, and this process is accelerated in multiple pregnancies, after haemorrhage, or in women with haemolytic anaemia. Secondly, an insufficient intake of folic acid, due to poor diet in pregnancy, plays a part in many cases. The third, and possibly the most important, factor is an absorption defect. Folic acid absorption is usually impaired in established cases, and this can still be demonstrated years later in a majority of patients, when they are neither pregnant nor anaemic. More than $20 \%$ of all cases also show abnormal fat absorption.

An inherited defect in folic acid absorption may also explain why certain women appear to be constitutionally predisposed to megaloblastic anaemia of pregnancy and the puerperium, as shown by the abnormal blood group distribution in these patients and by the tendency of megaloblastic anaemia to recur not only in subsequent pregnancies, but, as in six of our cases, following other kinds of stress.

The significance of commonly associated conditions like pre-eclampsia and infection is still incompletely understood. Although the treatment of megaloblastic anaemia is simple and effective, the main emphasis should be placed on prophylaxis by administering folic acid to all pregnant women.

The advent of modern methods in the diagnosis of vitamin $B_{12}$ and folic acid deficiency during the last decade has led to a better understanding of the megaloblastic anaemias. One of the most important advances in this field has been the observation by Chanarin, MacGibbon, O'Sullivan, and Mollin (1959) that most women become folic-acid-deficient in late pregnancy. This discovery provided an explanation for the high incidence of megaloblastic anaemia in pregnancy and the puerperium, a disease which has been the subject of a long-term study in north Staffordshire. Since 1957 well over 1,000 cases of anaemia in pregnancy have been investigated in this hospital. The present paper summarizes the findings in 335 cases of megaloblastic anaemia which have been diagnosed since the investigation began, and an attempt is made to explain the aetiology of the disease in the light of the experience gained during the last eight years.

\section{METHOD OF INVESTIGATION}

The investigation was conducted on the same lines as described in an earlier communication (Giles and Shuttleworth, 1958). Diagnosis was based on marrow aspiration in all but 10 cases where classical megaloblasts were found in the peripheral blood. Laboratory studies also included repeated haemoglobin estimations, blood and reticulocyte counts, serum iron estimations (Ramsay, 1953 ; 1954), bacteriological examination of urine, and faecal fat estimations. From 1960 onwards the serum vitamin $\mathbf{B}_{12}$ concentrations, using Euglena gracilis, z strain (Hutner, Bach, and Ross, 1956) and, since 1961, 
the serum folate level (Baker, Herbert, Frank, Pasher, Hutner, Wasserman, and Sobotka, 1959; Waters and Mollin, 1961) were determined in every case. Labile folate levels were estimated according to the method of Ball and Giles (1964). Folic acid absorption was determined by a modification of the method described by Chanarin, Anderson, and Mollin (1958) and Chanarin et al. (1959), using Lactobacillus casei instead of Streptococcus faecalis as the test organism.

\section{CLASSIFICATION OF MEGALOBLASTIC ANAEMIA}

The appearance of the bone marrow in megaloblastic anaemia in pregnancy varies, according to the degree of folic acid depletion, from florid megaloblastosis to minimal changes in both erythroblasts and myeloid cells (Dawson, 1962) and provides a convenient method of classification, which has already been described elsewhere (Giles, 1960; Ball and Giles, 1964). Table I summarizes the number of patients in each category. Cases classified as 'doubtful' have been excluded from the analysis.

\section{TABLE I}

\begin{tabular}{clc}
\multicolumn{3}{c}{ CLASSIFICATION OF MEGALOBLASTIC ANAEMIA } \\
Grade & Cytology & $\begin{array}{c}\text { No. of } \\
\text { Cases }\end{array}$ \\
\hline 3 & With florid megaloblastic marrow & 133 \\
2 & With transitional megaloblastic marrow & 92 \\
1 & $\begin{array}{l}\text { With mixed normoblastic and } \\
\text { megaloblastic marrow }\end{array}$ & 100 \\
Unclassified & $\begin{array}{l}\text { No marrow, megaloblasts in } \\
\text { peripheral blood }\end{array}$ & 10 \\
Doubtful & $\begin{array}{l}\text { With only minimal megaloblastic } \\
\text { changes }\end{array}$ & 37 \\
Controls & $\begin{array}{l}\text { With normoblastic marrow } \\
\text { Can }\end{array}$ & 669
\end{tabular}

THE INCIDENCE OF MEGALOBLASTIC ANAEMIA IN PREGNANCY

In view of the high incidence of megaloblastic anaemia of pregnancy in north Staffordshire (Giles and Shuttleworth, 1958), it was decided in 1958 to administer folic acid prophylactically during the last trimester of pregnancy to every alternate woman attending the hospital antenatal clinics (Giles and Burton, 1960). When a 12 months' trial had demonstrated the success of this regimen, all antenatal patients were given prophylactic folic acid from 1959 onwards.

Consequently, megaloblastic anaemia completely disappeared among the regular attenders at the hospital antenatal clinics. With the passage of years an increasing number of general practitioners also began to dispense folic acid to their patients, and the disease is now becoming relatively uncommon in this area. This is illustrated in Fig. 1, which shows a fall in the incidence of megaloblastic anaemia of

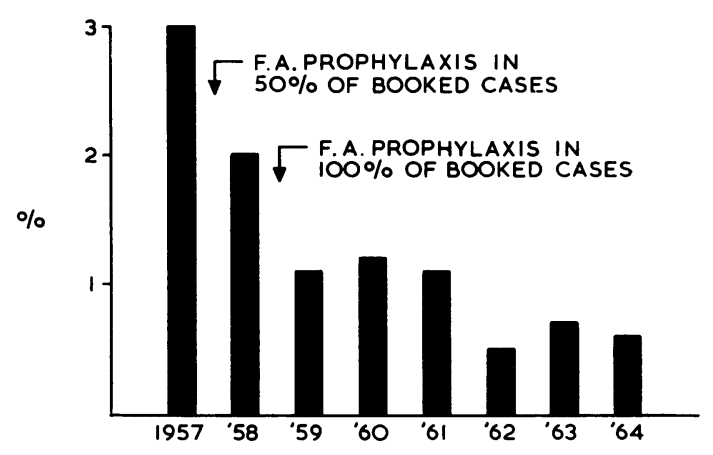

FIG. 1. The incidence of megaloblastic anaemia in hospital deliveries.

pregnancy from $3 \%$ in 1957 to $0.6 \%$ in 1964 of all women delivered in the main obstetric unit. Although these figures provide a valid comparison within the eight years in question, they are almost certainly an underestimate of the true incidence of the disease.

\section{CLINICAL FINDINGS}

AGE DISTRIBUTION The youngest patient was 15 , the oldest 45 years old. The mean age of 28.7 years was practically the same as that in the control group of normoblastic anaemias.

PARITY The only notable difference between women with megaloblastic anaemia of pregnancy and those with normoblastic anaemia was a higher incidence of primigravidae among the latter group.

SYMPTOMS AND SIGNS The two most characteristic clinical findings were stomatitis and anorexia. Thirtyslx per cent of patients with megaloblastic anaemia of pregnancy complained of a sore mouth or tongue, but less than $1 \%$ of those with normoblastic anaemia. The incidence and intensity of the stomatitis ran parallel with the severity of the anaemia. $\rightarrow$ Anorexia occurred in $30 \%$ of cases and sometimes aggravated an already established dietary deficiency, N although usually it appeared to be the result rather than the cause of folic acid deficiency. Aphonia was observed in two patients and remitted after treatment of the anaemia. Three women presented with $\underset{2}{2}$ purpura, which in two cases was accompanied by 0 thrombocytopenia and responded to folic acid therapy.

TIME OF ONSET As shown in Fig. 2, the disease was $\frac{7}{0}$ seldom seen before the 29th week of gestation; in five patients it was diagnosed between the 26th and $\stackrel{\mathbb{Q}}{\Omega}$ 28 th weeks, in one during the 24th week, and one patient with congenital spherocytosis presented 


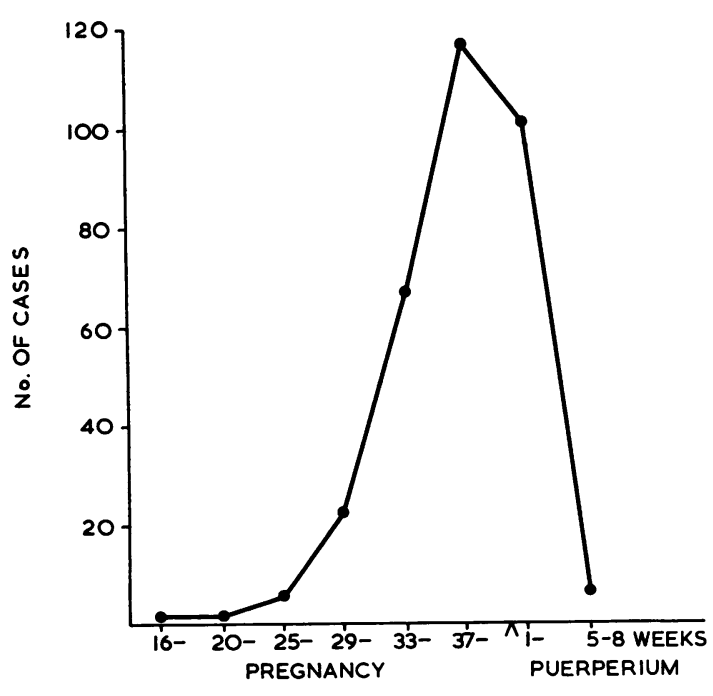

FIG. 2. Time of onset.

with megaloblastic anaemia during the 16th week. The peak incidence was during the four weeks before and after delivery. There was no correlation between the severity of the anaemia and the stage of pregnancy at which it occurred.

MORTALITY The immediate maternal mortality was nil. The only death occurred in a 37-year-old woman who presented with severe florid megaloblastic anaemia of pregnancy ( $\mathrm{Hb} 28 \% ; 4.1 \mathrm{~g} . \%)$ during the 28th week of her third pregnancy. She responded rather slowly to folic acid and iron therapy and was delivered of a normal infant at term. She died 13 weeks after delivery; necropsy revealed subacute bacterial endocarditis.

STILLBIRTHS, PREMATURITY AND FOETAL MALFORMATIONS As shown in Table II, the rate of stillbirths among patients with megaloblastic anaemia of pregnancy was more than twice that of all women confined in hospital. There was, however, no obvious increase in the incidence of premature delivery, nor does the present series of cases suggest that folic

TABLE II

INCIDENCE OF STILLBIRTHS, PREMATURE DELIVERY, AND FOETAL MALFORMATIONS

Megaloblastic All Hospital

Anaemias (\%) Deliveries

1960-64 (\%)

\begin{tabular}{lll}
\hline Stillbirths & $8 \cdot 3$ & $3 \cdot 8$ \\
Premature deliveries & $7 \cdot 7$ & $7 \cdot 2$ \\
Foetal malformations & $2 \cdot 5$ & $2 \cdot 0$
\end{tabular}

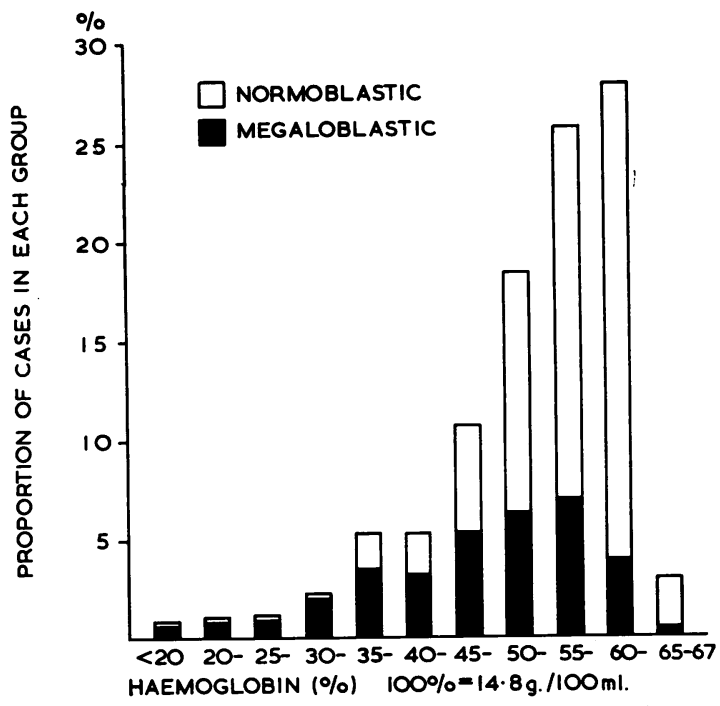

FIG. 3. Distribution of haemoglobin levels in 1,004 cases of pregnancy anaemia.

acid deficiency has a teratogenic effect on the foetus, as claimed by Fraser and Watt (1964).

\section{LABORATORY DIAGNOSIS}

DEGREE OF ANAEMIA By definition, patients were included in this survey only if their haemoglobin level was $67 \%(10.0 \mathrm{~g} . \%)$ or less. Figure 3 illustrates the haemoglobin distribution in 1,004 cases, comprising 335 women with megaloblastic anaemia of pregnancy and 669 with normoblastic anaemia. In 719 cases the haemoglobin level was over $50 \%$ $(7.4$ g. $\%)$ and in 557 of these the marrow was normoblastic. With a haemoglobin below $50 \%$, however, megaloblastic was more common than normoblastic anaemia (163 of 255 cases), and the marrow was almost invariably megaloblastic when the presenting haemoglobin was less than $35 \%$ $(5 \cdot 2 \mathrm{~g} . \%)$. Thus megaloblastic anaemia of pregnancy accounted for most of the severe anaemias, even those associated with haemorrhage.

Although the mean haemoglobin level in patients with megaloblastic anaemia of pregnancy varied according to the degree of megaloblastosis (Table III) not all cases conformed to this pattern. Ten patients with florid megaloblastic anaemia had haemoglobin levels above $60 \%$ and in seven cases with grade 1 megaloblastosis it was below $40 \%$. The severity of the anaemia in any given case, therefore, depends not only on the degree of folic acid depletion but also on the amount of blood loss associated with confinement, which is often underestimated. Haemoglobin levels certainly tended to be lower when the 
TABLE III

CORRELATION BETWEEN HAEMOGLOBIN LEVEL AND MARROW PICTURE ${ }^{1}$

\begin{tabular}{lclll} 
Marrow & $\begin{array}{c}\text { No. of } \\
\text { Cases }\end{array}$ & $\begin{array}{l}\text { Lowest } \\
\text { Hb }(\%)\end{array}$ & $\begin{array}{l}\text { Highest } \\
\text { Hb }(\%)\end{array}$ & $\begin{array}{l}\text { Mean } \\
\text { Hb (\%) }\end{array}$ \\
\hline Megaloblastic, grade 3 & 133 & 12 & 63 & $43 \cdot 7$ \\
Megaloblastic, grade 2 & 92 & 25 & 67 & $50 \cdot 0$ \\
Megaloblastic, grade 1 & $1 C 0$ & 25 & 67 & $52 \cdot 7$ \\
Megaloblastic, all cases & 335 & 12 & 67 & $48 \cdot 2$ \\
Normoblastic & 669 & 25 & 67 & $56 \cdot 1$
\end{tabular}

${ }^{1} \mathrm{Hb} 100 \%=14.8 \mathrm{~g} . \%$

'Including 10 cases without marrow biopsy

disease developed during the puerperium. In many cases other factors, such as iron deficiency and urinary infection, contributed to the anaemia.

BLOOD AND MARROW CHANGES The usual blood picture in megaloblastic anaemia of pregnancy was one of orthochromic normocytic anaemia with more anisocytosis than is seen in simple iron deficiency. Macrocytosis, blue polychromasia (Davidson, 1959) of red cells, and hypersegmentation of polymorphs was never observed in patients with grade 1 marrows, but frequently in cases with more marked megaloblastosis. Only in florid cases were megaloblasts found in the reripheral blood. In less than half the cases could a firm diagnosis have been made on the basis of the blood examination alone.

Examination of marrow films provided easy and instant diagnosis in all cases with predominantly megaloblastic erythropoiesis. Diagnostic difficulties arose only in marrows with partial megaloblastosis, as there is no sharp dividing line between normoblastic and transitional megaloblastic erythropoiesis. In the present series, all cases in which transitional megaloblasts numbered less than $10 \%$ of all erythroblasts have been classified as 'doubtful' and excluded from the analysis.

SERUM FOLATE LEVELS The range of serum folate levels and the mean values in 100 cases of megaloblastic anaemia of pregnancy and the puerperium are shown in Table IV together with a similar

\section{TABLE IV}

\section{SERUM FOLATE LEVELS}

\begin{tabular}{|c|c|c|c|c|}
\hline Group & $\begin{array}{l}\text { No. } \\
\text { of } \\
\text { Cases }\end{array}$ & $\begin{array}{l}\text { Range of } \\
\text { Folate } \\
\text { Levels } \\
\text { (mug. per }\end{array}$ & $\begin{array}{l}\text { Mean } \\
\text { Folate } \\
\text { ml.) }\end{array}$ & S.D. \\
\hline $\begin{array}{l}\text { Healthy controls (non-pregnant) } \\
\text { Normoblastic pregnancies } \\
\text { Megaloblastic pregnancies, all cases } \\
\text { Megaloblastic pregnancies, grade } 3 \\
\text { Megaloblastic pregnancies, grade } 2 \\
\text { Megaloblastic pregnancies, grade } 1 \\
\text { Megaloblastic pregnancies, } \\
\text { unclassified }\end{array}$ & $\begin{array}{r}58 \\
170 \\
100 \\
44 \\
20 \\
26 \\
\\
10\end{array}$ & $\begin{array}{l}3 \cdot 4-11 \cdot 6 \\
1 \cdot 6-7 \cdot 2 \\
0 \cdot 3-2 \cdot 4 \\
0 \cdot 3-1 \cdot 5 \\
0 \cdot 4-1 \cdot 8 \\
0 \cdot 5-2 \cdot 4 \\
0 \cdot 6-1 \cdot 6\end{array}$ & $\begin{array}{l}6 \cdot 6 \\
3.6 \\
1.0 \\
0.8 \\
1.0 \\
1.3 \\
1.0\end{array}$ & $\begin{array}{l}1.9 \\
0.4 \\
0.5 \\
0.4 \\
0.3 \\
0.6\end{array}$ \\
\hline
\end{tabular}

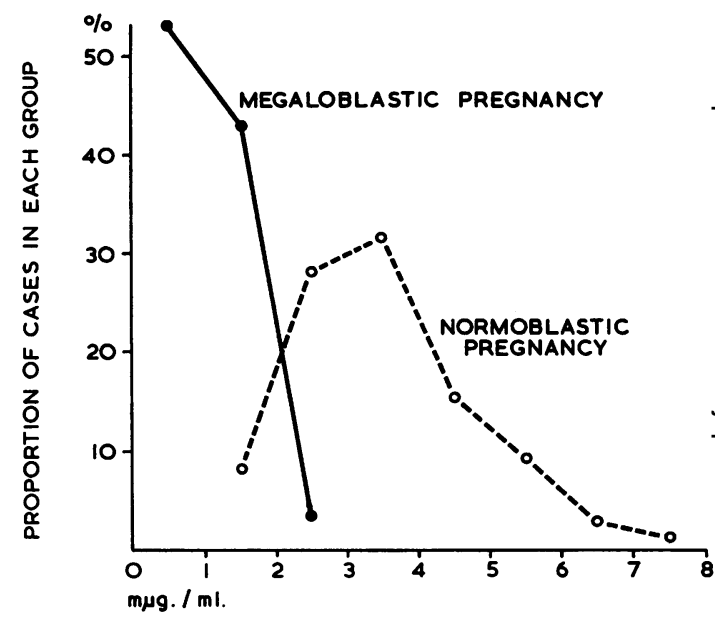

FIG. 4. Serum folate levels.

analysis of 58 healthy members of the hospital staffe and of 170 pregnant women with normoblastic marrows. The mean serum folate of all normo-o blastic pregnancies was $3.6 \mathrm{~m} \mu \mathrm{g}$. per ml., which is. significantly lower $(P<0.01)$ than that of the healthyo controls and is also significantly above the mean folate level in cases of megaloblastic anaemia $(P<\overline{0}$ 0.01 ). Moreover there was a good correlationô between mean folate levels and the degree of megalo- $\triangle$ blastosis. No cases of normoblastic anaemia had $a_{\vec{O}}$ serum folate below $1.5 \mathrm{~m} \mu \mathrm{g}$. per ml., and in megalo- blastic anaemia of pregnancy no folate levels above $2.4 \mathrm{~m} \mu \mathrm{g}$. per ml. were encountered. Between these two values, however, there was an overlap, which is illustrated in Figure 4.

In order to improve the sensitivity of the test, the labile folate was estimated by the method of Ballo and Giles (1964). Labile folate has been identified? as 5-methyl-tetrahydrofolic acid (Herbert, Larrabee, and Buchanan, 1962; Herbert, 1964) and is probablys related to folic acid coenzyme. Labile factor was estimated in 50 normoblastic and 66 megaloblastic pregnancies and the results are shown in Figure $5 \mathrm{~N}$ The overlap between the two groups is much smaller than in the case of the total folate assay. With 1.20 $\mathrm{m} \mu \mathrm{g}$. per $\mathrm{ml}$. as the dividing line, only five of $116 \mathrm{w}$ cases would have been wrongly diagnosed by this? test.

VITAMIN $\mathrm{B}_{12}$ CONCENTRATION The mean vitamin $\mathrm{B}_{12} \stackrel{\mathbb{f}}{?}$ concentration in 155 cases of megaloblastic anaemia of pregnancy was $200 \mu \mu \mathrm{g}$. per ml., which is? significantly below the mean value of $265 \mu \mu \mathrm{g}$. per乃 $\mathrm{ml}$. for 220 pregnant women with normoblastic marrows $(P<0.01)$. Nevertheless, the overlap of serum levels between megaloblastic and normo- 


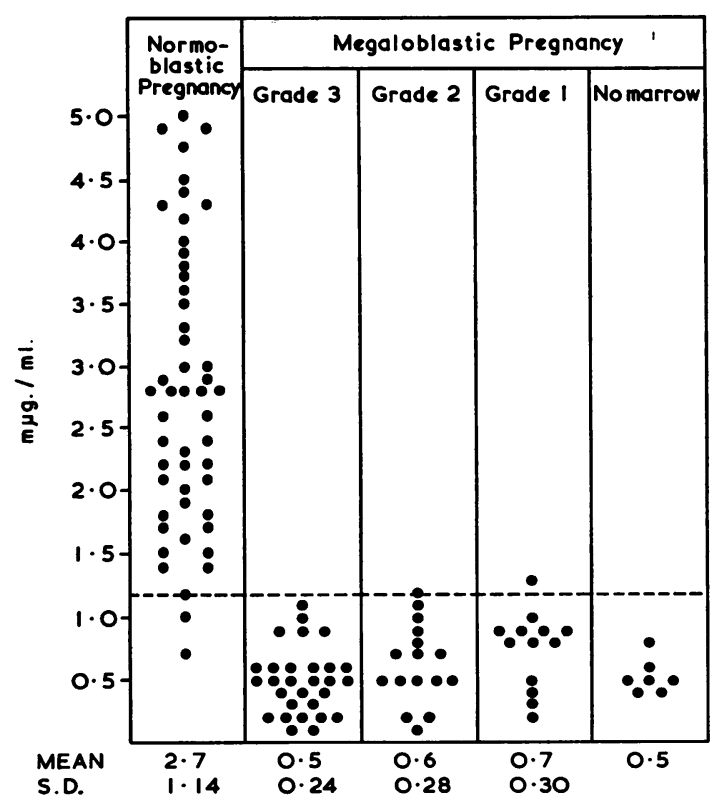

FIJ. 5. Labile folate levels.

blastic pregnancies was so great that, from a diagnostic point of view, the test was of little value. In nine patients with megaloblastic anaemia of pregnancy the vitamin $B_{12}$ ranged between 50 and $100 \mu \mu \mathrm{g}$. per ml.; in three of these Addisonian anaemia was excluded by gastric analysis and in two others by radioactive vitamin $B_{12}$ studies. In all nine cases the serum vitamin $B_{12}$ rose to normal levels on folic acid therapy alone.

SERUM IRON LEVEL In most types of megaloblastic anaemia the serum iron concentration is increased and, therefore, provides a useful diagnostic guide. In pregnancy, folic acid and iron deficiency frequently go together and, when that happens, the serum iron level largely depends on the degree of megaloblastosis. In florid mezaloblastic anaemia of pregnancy with complete erythropoietic arrest the serum iron level is almost invariably normal or increased; only in the milder cases, where many erythroblasts remain unaffected and mature at a normal rate, does the serum iron level reflect the degree of the accompanying iron deficiency. The mean serum iron level in megaloblastic anaemia of pregnancy was $204 \mu \mathrm{g} . \%$; in 179 of 293 cases it exceeded $150 \mu \mathrm{g} . \%$ and in 69 it ranged between 300 and $450 \mu \mathrm{g} . \%$. Such very high serum iron levels are seldom seen in other types of megaloblastic anaemia, and in the disease associated with pregnancy they reflect the raised ironbinding capacity of plasma in pregnancy. In many cases iron therapy undoubtedly contributed to the high serum iron level, although patients who had received parenteral iron have not been included in this analysis.

A second serum iron estimation was performed in 129 patients, two or three days after the beginning of folic acid therapy. Most cases showed a fall in the serum iron level ranging from 10 to $300 \mu \mathrm{g} . \%$, with a mean of $102 \mu \mathrm{g} . \%$. Before the introduction of folate assays, the fall in the serum iron concentration was a most useful diagnostic test and provided a rapid indication of the individual patient's response to therapy.

\section{AETIOLOGY OF MEGALOBLASTIC ANAEMIA IN PREGNANCY}

Megaloblastic anaemia in pregnancy and the puerperium is in practice always due to a deficiency of folic acid (Lowenstein, Pick, and Philpott, 1955; Gatenby and Lillie, 1960), which may be produced by an increased demand for this vitamin, by insufficient intake, or by malabsorption.

EXCESSIVE DEMAND FOR FOLIC ACID In every pregnancy the developing foetus makes increasing demands on the maternal stores of folic acid. Baker, Ziffer, Pasher, and Sobotka (1958) were the first to demonstrate high folate levels in foetal blood, even when the mother was folic-acid-deficient. These findings have been confirmed in our laboratory where paired specimens of maternal and cord blood have been examined for their folate content (E. W. Ball, unpublished observations); 25 of these were from normal pregnancies, one from a normal twin pregnancy, and one from a case of megaloblastic anaemia of pregnancy. The results are shown in Figure 6. Maternal blood levels ranged from 0.9 to $6.2 \mathrm{~m} \mu \mathrm{g}$. per $\mathrm{ml}$. with a mean of $3.5 \mathrm{~m} \mu \mathrm{g}$. per $\mathrm{ml}$. (S.D. $=1 \cdot 1$ ),

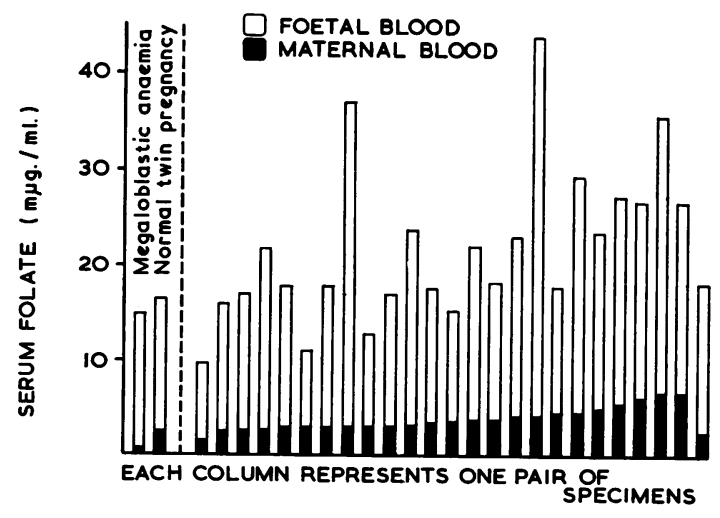

FIG. 6. Folate levels in maternal and cord blood. 
and cord blood levels from 7.7 to $40.0 \mathrm{~m} \mu \mathrm{g}$. per $\mathrm{ml}$. with a mean of $17 \cdot 1 \mathrm{~m} \mu \mathrm{g}$. per $\mathrm{ml}$. (S.D. $=9 \cdot 1$ ). The ratio of mean foetal/mean maternal folate was $4 \cdot 9 / 1$. These findings suggest that the developing foetus has a high avidity for folic acid.

Twin pregnancies Intense folic acid depletion in women with multiple pregnancies (Chanarin et al., 1959 ) is reflected in a higher incidence of megaloblastic anaemia of pregnancy among twin pregnancies (Girdwood, 1956; Scott, 1957). In 12 normal twin pregnancies examined in this laboratory the mean folate level was $2.4 \mathrm{~m} \mu \mathrm{g}$. per $\mathrm{ml}$., compared with $3.4 \mathrm{~m} \mu \mathrm{g}$. per $\mathrm{ml}$. in a group of normal single pregnancies at the corresponding stage of gestation (Ball and Giles, 1964). The present series of 1,004 anaemias of pregnancy included 44 twin pregnancies, 24 of which were complicated by megaloblastic anaemia, an incidence of $55 \%$. This is significantly greater then the incidence in 960 women with single pregnancies, $32 \%$ of whom developed megaloblastic anaemia $(P<0.01)$.

Haemolytic anaemia and haemorrhage Abnormally active haemopoiesis, as seen in haemolytic anaemia and leukaemia, can lead to folic acid deficiency with or without megaloblastosis. A pregnant woman with haemolytic anaemia is, therefore, specially liable to develop megaloblastic anaemia (Davidson, 1952; Drury and Geoghegan, 1957; Kohler, Meynell, and Cooke, 1960). The present series includes a woman with familial spherocytosis who developed florid megaloblastic anaemia with her first two pregnancies. She presented again at the age of 26 during the sixteenth week of her third pregnancy with a haemoglobin level of $45 \%(6.7$ g. $\%)$, with reticulocytosis, icterus, and a grade 1 megaloblastic marrow. Splenectomy was performed two weeks later, her marrow became normoblastic, and she went to term with a normal haemoglobin and blood picture. A subsequent pregnancy has been uneventful.

Haemorrhage is the commonest stimulus which produces increased marrow activity. In 15 cases of post-partum haemorrhage the fall in the haemoglobin concentration was much greater than the observed blood loss appeared to warrant; marrow aspiration in these cases revealed megaloblastic erythropoiesis. Since moderate blood loss accompanies most confinements this factor probably plays a part in the aetiology of megaloblastic anaemia which develops during the puerperium.

LOW INTAKE OF FOLIC ACID Earlier results of the present investigation (Giles and Shuttleworth, 1958) had shown that a high proportion of patients with megaloblastic anaemia of pregnancy had taken aninadequate diet during pregnancy. Attempts $t \overrightarrow{\vec{\omega}^{2}}$ improve the diet of expectant mothers by repeated instructions in the antenatal clinic have met witlo only partial success, for even in recent years manyes patients gave a history of having taken a very pook diet throughout pregnancy, which included onlyo two meat meals a week or less, few eggs, and verys little fresh fruit and vegetables. A history of an $\overrightarrow{0}$ inadequate diet was obtained in $30 \%$ of 301 patients with megaloblastic anaemia of pregnancy, but inf only $17 \%$ of 560 patients with normoblastic anaemiक $(P<0.001)$. Anorexia and stomatitis, which are early symptoms of megaloblastic anaemia of pregse nancy, tend to exacerbate any pre-existing malnutrition. Sometimes vomiting may also play a parto in reducing the intake of food of a patient.

MALABSORPTION Folic acid absorption was studiede in 13 healthy controls, nine normal pregnant women 11 cases of megaloblastic anaemia of pregnancy, and 10 other cases of folic-acid-deficiency anaemia. Theo folic acid uptake in the normal pregnancies, with $a^{\circ}$ mean maximum folate of $95 \mathrm{~m} \mu \mathrm{g}$. per ml. was lower than in the normal controls (mean 172 $\mathrm{m} \mu \mathrm{g}$. per $\mathrm{ml}$.), but significantly lower still $(\mathrm{P}<0.01)$ was the folic acid uptake in megaloblastic anaemia of pregnancy (mean $42 \mathrm{~m} \mu \mathrm{g}$. per ml.) and in the other folic-acid-deficiency anaemias (mean $60 \mathrm{~m} \mu \mathrm{g}$. per $\overrightarrow{\vec{O}}$ $\mathrm{ml}$.) most of which were associated with steatorrhoea. 3 This confirms the findings of Chanarin and his coworkers (1959). In the present series, nine of 1 10 patients with megaloblastic anaemia of pregnancy showed a lower folic acid absorption than any of? the patients with normal pregnancies. The results in this admittedly small group of cases suggest, therefore, that the absorption of folic acid is impaired? in the majority of women who develop megaloblastic anaemia in pregnancy. In order to establish whether this absorption defect is permanent or merely a temporary phenomenon associated with pregnancy, folic acid absorption studies were also carried out in N seven women who had been treated for megaloblastic anaemia of pregnancy from one to three years previously and who had not been pregnant in the ${ }^{\omega}$ meantime. In all seven cases the haemoglobin was? normal (90 to $109 \%$ ), but, as shown in Fig. 7, folice acid absorption (mean maximum folate $62 \mathrm{~m} . \mu \mathrm{g}$ per $\mathrm{ml}$.) was lower than in any of the normal ${ }^{+}$ controls.

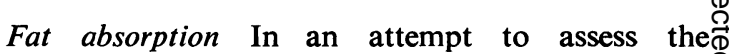
incidence of general malabsorption, the daily faecal $\stackrel{\circ}{\sigma}$ fat output was estimated in 83 patients with megalo- 


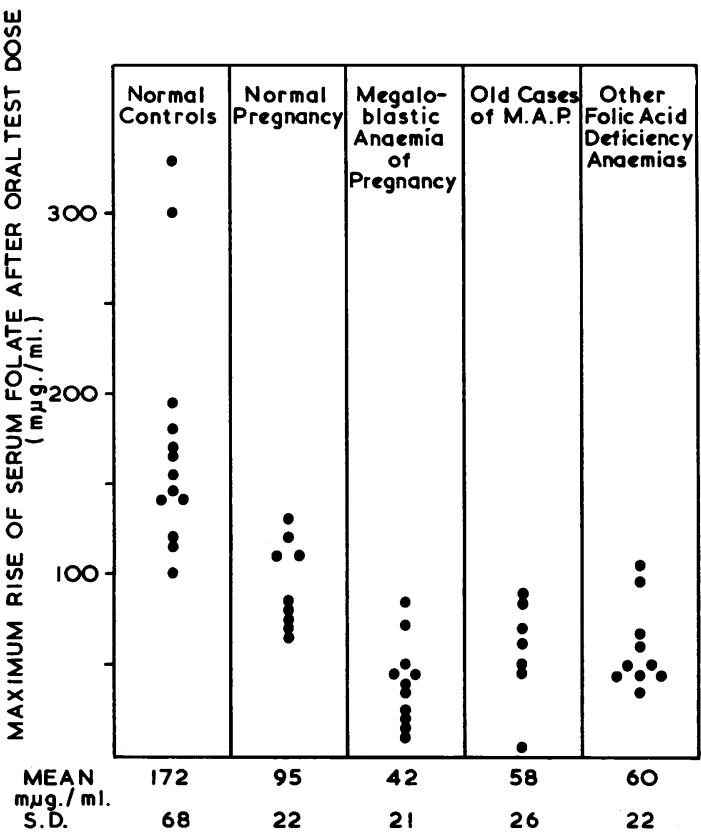

FIG. 7. Folic acid absorption tests.

blastic anaemia of pregnancy and in 27 with normal pregnancies. The specimens were collected over a three-day period while patients were taking a normal mixed diet. The results are summarized in Table $\mathrm{V}$, which shows that the mean daily faecal fat output of patients with megaloblastic anaemia of pregnancy was nearly twice that in normal pregnant women. The upper limit of normal fat excretion is generally regarded as $6 \mathrm{~g}$. per day and this was exceeded in only one of the 27 normal pregnancies, compared with 18 of the 83 cases of megaloblastic anaemia of pregnancy $(22 \%)$; eight of the latter had frank steatorrhoea. The difference between the two groups is undoubtedly significant $(P<0.01)$ and suggests impaired fat absorption in at least a proportion of cases of megaloblastic anaemia.

\section{TABLE V}

DAILY FAECAL FAT EXCRETION

$\begin{array}{lll}\text { Group } & \begin{array}{l}\text { No. } \\
\text { of } \\
\text { Cases }\end{array}\end{array} \quad$\begin{tabular}{l} 
Faecal Fat Output (g.per day) Highest Mean S.D. \\
$\begin{array}{l}\text { Lowes with } \\
\text { Output of } \\
\text { Over } 6 \mathrm{~g} . \\
\text { per Day }\end{array}$ \\
\hline
\end{tabular}

\begin{tabular}{lrrrrrr}
\hline $\begin{array}{l}\text { Megaloblastic } \\
\text { anaemia }\end{array}$ & 83 & 1.1 & 13.6 & 4.4 & 2.4 & 18 \\
$\begin{array}{l}\text { Normal } \\
\text { pregnancy }\end{array}$ & 27 & 0.9 & 6.5 & 2.5 & 1.0 & 1
\end{tabular}

CONSTITUTIONAL FACTORS

All pregnant women are prone to develop folic acid deficiency, but there is evidence to suggest that some are more liable to megaloblastic anaemia than others; namely, the tendency of the disease to recur in subsequent pregnancies (Forshaw, Jones, Chisholm, and McGinley, 1957) and the presence of an abnormal blood group distribution.

RECURRENT MEGALOBLASTIC ANAEMIA In 22 patients of the present series two or more pregnancies were complicated by megaloblastic anaemia; in 18 of these the relapses were studied personally and, in the remaining four, marrow films and medical records were available. In a further 13 cases the previous history was strongly suggestive of the disease, even if definitive proof could not be obtained (Table VI). Allowing for the primigravidae in the present series, whose fate in subsequent pregnancies is unknown, and for the widespread folic acid prophylaxis, the relapse rate is probably higher than the $11 \%$ recorded in this survey. The severity of the anaemia, the degree of megaloblastosis, and the stage of gestation at which the disease developed varied in the same patient from one attack to the next.

\section{TABLE VI}

RECURRENT MEGALOBLASTIC ANAEMIA IN PREGNANCY

\begin{tabular}{ll} 
No. of Attacks & No. of Cases \\
\hline 4 & 2 \\
3 & 3 (1 with congenital spherocytosis) \\
2 & 17 (14 included in this series) \\
2 probable & 13
\end{tabular}

Of particular interest, in this connexion, were six further women with megaloblastic anaemia of pregnancy who relapsed several years later while they were not pregnant (Table VII); in three of them the second attack of megaloblastic anaemia was known to be associated with steatorrhoea, in two the faecal fat had not been estimated. In two cases the anaemia developed soon after an attack of pneumonia, in one it followed pleurisy, a fourth had been on prolonged barbiturate therapy, and a fifth was being treated for generalized eczema. Cases of this kind have been described in the past (Callender, 1944; Segerdahl, 1941) and they demonstrate that pregnancy is only one type of stress capable of evoking megaloblastic anaemia in certain people who appear to be constitutionally predisposed. It is probably no coincidence that in at least half of the cases here reported there was evidence of intestinal malabsorption. 
TABLE VII

RELAPSE OF MEGALOBLASTIC ANAEMIA IN THE ABSENCE OF PREGNANCY

\begin{tabular}{|c|c|c|c|c|c|c|c|}
\hline \multirow[t]{2}{*}{ Case } & \multicolumn{2}{|c|}{$\begin{array}{l}\text { Attack During } \\
\text { Pregnancy }\end{array}$} & \multicolumn{5}{|c|}{ Subsequent Attack While Not Pregnant } \\
\hline & $\mathrm{Hb}(\%)$ & $\overline{A g e}(y r)$. & Precipitating Factor & $H b(\%)$ & Age & Faecal Fat (g./day) & $\begin{array}{l}\text { Serum Folate } \\
(m \mu g . / m l .)\end{array}$ \\
\hline $\begin{array}{l}\text { V.B. } \\
\text { W.T. } \\
\text { D.R. } \\
\text { C.B. } \\
\text { I.R. }\{ \\
\text { G.W. }\end{array}$ & $\begin{array}{l}35 \\
57 \\
45 \\
- \\
62 \\
43\end{array}$ & $\begin{array}{l}30 \\
21 \\
22 \\
37 \\
20 \\
22 \\
24 \\
31\end{array}$ & $\begin{array}{l}\text { Pneumonia } \\
\text { Pleurisy } \\
\text { Barbiturate } \\
\text { Generalized eczema }\end{array}$ & $\begin{array}{l}43 \\
29 \\
35 \\
40\end{array}$ & $\begin{array}{l}40 \\
27 \\
26 \\
41\end{array}$ & $\begin{array}{r}10 \cdot 1 \\
2 \cdot 6 \\
7 \cdot 6 \\
8 \cdot 3\end{array}$ & $\begin{array}{l}0.9 \\
0.8 \\
- \\
-\end{array}$ \\
\hline
\end{tabular}

TABLE VIII

BLOOD GROUP DISTRIBUTION IN NORMAL PREGNANCY AND IN VARIOUS TYPES OF MEGALOBLASTIC ANAEMIA DIAGNOSED IN NORTH STAFFORDSHIRE 1957-65

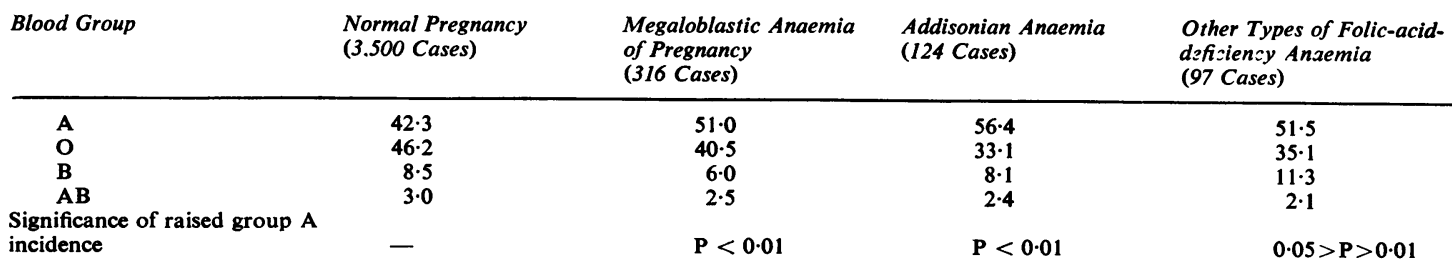

BLOOD GROUP DISTRIBUTION An abnormally high incidence of blood group A has been demonstrated in patients with Addisonian anaemia (Roberts, 1959) and a similar increase in the incidence of blood group A has been described in megaloblastic anaemia of pregnancy (Giles, 1960; Ainley, 1961). Table VIII shows the blood group distribution in 537 cases of megaloblastic anaemia, diagnosed in this laboratory between 1957 and 1965, and compares it with that of 3,500 routine antenatal patients in the same district. All types of megaloblastic anaemia show a raised incidence of blood group $\mathrm{A}$, which is most pronounced in cases of Addisonian anaemia. The blood group A preponderance in megaloblastic anaemia of pregnancy is of the same order as in other folic acid-deficiency anaemias associated with steatorrhoea, malnutrition, and anticonvulsant drug therapy, thus lending support to the suggestion that there is an inherited predisposition to folic acid deficiency anaemia.

\section{ASSOCIATED CONDITIONS}

Any condition which increases the demand for folic acid or in any way interferes with erythropoiesis could precipitate megaloblastic anaemia in a pregnant woman whose folic acid stores are already depleted. Two of these conditions, haemorrhage and haemolytic anaemia, have already been mentioned. Infection, especially urinary infection, is commonly associated with anaemia in pregnancy (Scott, 1961; Giles and Brown, 1962) and especially with megaloblastic anaemia (Gatenby and Lillie, 1960; Ainley, 1961). Table IX shows the incidence of infection in 861 cases of pregnancy anaemia in the present series, which was $9.5 \%$ in megaloblastic anaemia of pregnancy and $5.8 \%$ in normoblastic anaemias. This is a lower incidence than that reported by other workers, notably Scott (1961), who found associated infection in $45 \%$ of all cases of pregnancy anaemias.

\section{TABLE IX}

PERCENTAGE INCIDENCE OF INFECTION AND PRE-ECLAMPSIA IN PREGNANCY ANAEMIA

\begin{tabular}{lcc} 
Condition & $\begin{array}{l}\text { Megaloblastic } \\
\text { (287 Cases) }\end{array}$ & $\begin{array}{l}\text { Normoblastic } \\
\text { (574 Cases) }\end{array}$ \\
\hline Urinary infection & $7 \cdot 3$ & 4.4 \\
Breast abscess & 0.5 & - \\
Uterine infection & 0.5 & 0.6 \\
Thrombophlebitis & 0.7 & 0.4 \\
Pneumonia & 0.5 & 0.4 \\
Pre-eclamptic toxaemia & 12.2 & 14.0
\end{tabular}

PRE-ECLAMPTIC TOXAEMIA Several authors (Gatenby $\stackrel{\oplus}{\oplus}$ and Lillie, 1960; MacKenzie and Abbott, 1960; Ainley, 1961) have commented on the association between megaloblastic anaemia of pregnancy and pre-eclampsia. In the present series, the incidence of pre-eclampsia was $12.2 \%$ in cases of megaloblastic and $14.0 \%$ in those of normoblastic anaemia, which 
is again lower than the figures quoted by other authors.

ANTE-PARTUM HAEMORRHAGE Hibbard and Hibbard (1963) reported a constant relationship between abruptio placentae and folic acid deficiency with or without megaloblastic anaemia. In the present series, ante-partum haemorrhage of all types occurred in only $4 \%$ of cases of megaloblastic and $5 \%$ of those of normoblastic anaemia. The serum folate level of 21 random cases of abruptio placentae in this hospital was found to be low in only two patients, and their mean folate level of $3 \cdot 1 \mathrm{~m} \mu \mathrm{g}$. per. ml. was only slightly less than the expected mean of $3.3 \mathrm{~m} \mu \mathrm{g}$. per $\mathrm{ml}$. of normal women at the same stage of gestation (E. W. Ball, unpublished observation). It is also relevant in this connexion that during the last few years numerous cases of abruptio placentae occurred among women who had taken prophylactic folic acid for several weeks before admission and that the overall incidence of ante-partum haemorrhage has remained the same since routine folic acid therapy was instituted.

ANTICONVULSANT DRUG THERAPY Gatenby (1960) found a high incidence of megaloblastic anaemia in pregnant epileptics receiving hydantoin therapy. Since this survey began 17 cases of megaloblastic anaemia have been observed in this hospital in epileptics on hydantoin or primidone therapy, but only one of these patients was a pregnant woman.

IRON AND VITAMIN $B_{12}$ DEFICIENCY There was no evidence in the present series of cases that iron deficiency predisposed to folic acid deficiency, as was recently claimed by Chanarin, Rothman, and Berry (1965), for both megaloblastic anaemia and low serum folate levels were commoner among 620 pregnant women who had taken iron supplements in pregnancy than in 254 women who had not. In fact, there was, if anything, an inverse relationship between serum iron and folate levels.

Although the serum vitamin $B_{12}$ concentration was abnormally low in many of our cases of folic acid deficiency anaemia, including megaloblastic anaemia of pregnancy, a true correlation could not be demonstrated between serum vitamin $B_{12}$ and folate levels.

\section{A COMBINATION OF FACTORS}

In the light of the present knowledge, it is impossible to assess the relative importance of the various aetiological factors which have been described. In many patients no specific cause other than late pregnancy could be found to explain the megalo- blastic anaemia. In at least $15 \%$ of cases, however, more than one factor appeared to operate, e.g., 12 patients with evidence of malabsorption and 16 with pre-eclampsia also gave a history of a poor diet in pregnancy, and in six cases of twin pregnancy, other factors, such as poor diet, infection, and preeclampsia, were also present.

\section{RESPONSE TO TREATMENT}

The response to folic acid therapy, as measured by the peak in the reticulocyte count, depended both on the severity of the anaemia and on the degree of megaloblastosis, as seen in Table $\mathrm{X}$. The mean rise

TABLE X

\begin{tabular}{|c|c|c|c|c|}
\hline \multicolumn{5}{|c|}{ MEAN MAXIMUM RETICULOCYTE RESPONSE ( $\%$ ) } \\
\hline Haemoglobin $(\%)$ & Grade 3 & Grade 2 & Grade 1 & All Grades \\
\hline $10-19$ & 22 & 一 & - & 22 \\
\hline 20-29 & 23 & 18 & - & 22 \\
\hline $30-39$ & 19 & 17 & 11 & 17 \\
\hline $40-49$ & 16 & 15 & 10 & 15 \\
\hline $50-59$ & 13 & 10 & 9 & 12 \\
\hline $60-67$ & 12 & 10 & 6 & 10 \\
\hline All cases & 17 & 14 & 9 & 15 \\
\hline
\end{tabular}

in the haemoglobin concentration after two weeks, therapy was $16 \%(2.4 \mathrm{~g} . \%)$ in patients with grade 3 megaloblastosis and $11 \%(1.6 \mathrm{~g} . \%)$ in grades 1 and 2 . Blood transfusion invariably retarded the haemopoietic response and so did pre-eclamptic toxaemia.

That vitamin $B_{12}$ has no place in the treatment of megaloblastic anaemia of pregnancy (Pritchard, 1962 ) is illustrated by five patients who were given vitamin $B_{12}$ in error at an early stage of the investigation. In two of them there was a suboptimal response, but in the other three the haemoglobin fell while it was being given; one of them was eventually admitted to hospital with a haemoglobin level of $17 \%$. A sixth patient had been diagnosed as having Addisonian anaemia at the age of 31 , a diagnosis which was not subsequently confirmed, and received $1,000 \mu \mathrm{g}$. of vitamin $\mathrm{B}_{12}$ at monthly intervals thereafter. When she had been on this regimen for a year she was admitted to hospital with megaloblastic anaemia of pregnancy and responded promptly to folic acid therapy.

\section{PROPHYLAXIS}

Routine folic acid prophylaxis during the last 14 weeks of pregnancy was begun in this hospital in 1958. The initial dosage of $15 \mathrm{mg}$. daily was subsequently reduced to $5 \mathrm{mg}$. per day and this is still our current practice. As yet there is no general agreement about the minimum requirements of folic 
acid in pregnant women. Lowenstein and his coworkers (1955) gave $3 \mathrm{mg}$. daily, but later (Lowenstein, Brunton, Cooper, Milad, and Hsieh, 1963) reduced it to $500 \mu \mathrm{g}$. Herbert (1964) estimated the daily requirement of a healthy adult as $50 \mu \mathrm{g}$. per day, whilst Chanarin and his colleagues (1965) found a dose of $20 \mu \mathrm{g}$. per day inadequate in pregnancy. Since folic acid is both cheap and virtually free from side-effects, it is probably wise to err on the generous side and administer $200 \mu \mathrm{g}$. to $1 \mathrm{mg}$. per day. During the past year several drug firms have marketed compound iron and folic acid tablets, each containing $50 \mu \mathrm{g}$. of folic acid. Such preparations are obviously convenient, but it is difficult to ensure that they are only taken by healthy pregnant women. Fortunately, perhaps, the prohibitive cost of these preparations will militate against their widespread use.

Opposition to wholesale folic acid prophylaxis, based on the fear that unrecognized cases of Addisonian anaemia might inadvertently be treated in this way, now appears to be on the wane (Brit. med. J., 1964), since large numbers of pregnant women all over the world have been treated with folic acid without any reported ill-effect. In this hospital alone well over 20,000 women have now been delivered since folic acid prophylaxis was adopted and not a single case of Addisonian anaemia has been discovered in any of them.

\section{CONCLUSIONS}

Experience in north Staffordshire during the past eight years has confirmed beyond any doubt that a deficiency of folic acid tends to develop in pregnancy together with iron deficiency. Once folic acid depletion becomes sufficiently severe, megaloblastic changes make their appearance in the bone marrow; these can vary greatly in intensity, sometimes affecting only a small proportion of erythroblasts and myeloid cells. In such cases anaemia need not be severe and is often due to recent haemorrhage or concomitant iron deficiency rather than to the megaloblastosis. However, when the marrow becomes predominantly megaloblastic, anaemia is usually severe and, in florid cases, often profound. In the latter group a presumptive diagnosis can usually be made on the basis of a severe orthochromic and sometimes macrocytic anaemia in a patient with stomatitis and anorexia, especially if there is a history of megaloblastic anaemia in previous pregnancies. A definitive diagnosis, however, usually requires confirmation by marrow aspiration or serum folate assay.

The main causes of folic acid depletion in pregnancy are the active synthesis of nucleoproteins by the developing foetus and the expanding bloof volume of the mother, which greatly increase herrequirement of folic acid. This process is even mor $\overrightarrow{\hat{E}_{5}}$ intense in multiple pregnancies, the majority of women showing relatively low serum folate levels $\frac{\ulcorner}{-}$ The rapidity with which the patient becomes folic $\overline{\text {. }}$. acid-deficient depends to a large extent on he dietary intake of this vitamin. In about a third of the cases in this series malnutrition probably played a part.

Blood loss at confinement, which need not be excessive, often tips the balance, plunges the patienf into profound folic acid deficiency and probably accounts for the prevalence of megaloblastic anaemi during the puerperium. Other precipitating factor $\overrightarrow{0}$ are concurrent blood dyscrasias, such as haemo-lytic anaemia, in which maternal haemopoiesis runs at an accelerated pace. Urinary and other infections, which are believed to interfere with erythropoiesis, may play a part in some patients It is difficult to say whether pre-eclamptic toxaemia which complicated over $12 \%$ of cases in this series? was a cause or an effect of the anaemia.

Intestinal malabsorption, which is a known caus of folic acid deficiency, is almost certainly concerned in the pathogenesis of megaloblastic anaemia of pregnancy. Pregnant women generally appear to absorb folic acid less efficiently than non-pregnan subjects; four of nine normal pregnant wome examined in this laboratory showed a lower folie acid uptake than the non-pregnant controls. I megaloblastic anaemia of pregnancy, however, the absorption defect appears to be even more marked abnormally low results were obtained in all the 19. patients whose folic acid absorption was estimateक and in nine of them it was lower than in any of the normal pregnant women. Fat absorption, on the other hand, was diminished in only 18 of 83 cases This suggests that in most cases malabsorption is confined to folic acid alone, whilst in a proportion of cases it is accompanied by general malabsorption?

It might be argued that malabsorption in megalos blastic anaemia of pregnancy is merely a temporar. phenomenon due to changes in the intestinat mucosa associated with pregnancy. Yet folic acido absorption was impaired in seven patients who wene examined several years after their last attack of megaloblastic anaemia of pregnancy and who showed no evidence of anaemia. Furthermore, si⿺ women with megaloblastic anaemia of pregnanos presented many years later with megaloblastic anaemia and folic acid deficiency while they were not pregnant and three of them had steatorrhoea It would thus appear that the absorption defect permanent and that all women with such a defeet are liable to develop megaloblastic anaemia undera 
variety of stresses of which pregnancy is only one, whilst malnutrition, infection, blood diseases, and certain drugs may play a similar part. This hypothesis also explains the high relapse rate of megaloblastic anaemia in subsequent pregnancies, which was over $11 \%$ in the present series, and also the blood group A preponderance not only in cases of megaloblastic anaemia of pregnancy but also in other folic-acid-deficiency anaemias.

Other theories have been advanced in the past in order to explain the pathogenesis of megaloblastic anaemia in pregnancy. Badenoch, Callender, Evans, Turnbull, and Witts (1955) postulated a tissue resistance to the action of folic acid, and Scott (1962) discussed the possibility of a block in the metabolism of folic acid initiated by folic acid deficiency. It is, however, difficult to reconcile the existence of a metabolic block with the consistently low levels of both $L$. casei-active (5-methyl-tetrahydrofolic acid) and Str. faecalis-active ('stable factor') folic acid in the sera of patients with megaloblastic anaemia of pregnancy and related megaloblastic anaemias. A block in the folate metabolism at tissue level would lead to piling-up of folic acid co-enzyme with a raised serum folate level, as described by Herbert and Zalusky (1962) in Addisonian anaemia. Similarly a block in the conversion of folic acid to active coenzyme might be expected to produce a corresponding rise in the Str. faecalis-active folate level of the serum, but in fact, the concentration of both types of folic acid derivatives is invariably low in this type of anaemia.

This investigation is the result of team work and, directly or indirectly, involved nearly every member of the laboratory staff. I am specially grateful to Dr. E. W. Ball, who established folote assays and evolved methods of determining labile folate and folic acid absorption, to Mr. P. H. Johnson, Mrs. Margaret Clowes, and to Mr. A. C. Key for the haematological work, to Miss Wendy Cooke and Miss Rosemary Thompstone for the vitamin assays, to Miss M. R. Haslock for the faecal fat estimations, and to my colleagues, Dr. J. A. H. Brown and Dr. A. J. McCall, for their constant help and advice.

This study would not have been possible without the help and encouragement of Mr. Harold Burton and the whole Obstetric Department of the hospital, and I wish to thank the Research Subcommittee of the Birmingham Regional Hospital Board, which for several years provided additional staff and equipment.

\section{REFERENCES}

Ainley, N. J. (1961). J. Obstet. Gynaec. Brit. Emp., 68, 254.

Badenoch, J., Callender, S. T., Evans, J. R., Turnbull, A. L., and Witts, L. J. (1955). Brit. med. J., 1, 1245.

Baker, H., Herbert, V., Frank, O., Pasher, I., Hutner, S. H., Wasserman, L. R., and Sobotka, H. (1959). Clin. Chem., 5, 275.

— 978.

Ball, E. W., and Giles, C. (1964). J. clin. Path., 17, 165.

British Medical Journal (1964). To-day's Drugs. Brit. med. J., 2, 1248.

Callender, S. T. E. (1944). Quart. J. Med., 13, 75.

Chanarin, I., Anderson, B. B., and Mollin, D. L. (1958), Brit. J. Haemat., 4, 156.

__, MacGibbon, B. M., O’Sullivan, W. J., and Mollin, D. L. (1959). Lancet, 2, 634.

-, Rothman, D., and Berry, V. (1965). Brit. med. J., 1, 480.

Davidson, E. (1959). J. clin. Path., 12, 322.

Davidson, L. S. P. (1952). Edinb. med. J., 59, 315

Dawson, D. W. (1962). J. Obstet. Gynaec. Brit. Cwlth, 69, 38.

Drury, M. I., and Geoghegan, F. (1957). Brit. med. J., 2, 393.

Forshaw, J. W. B., Jones, A. T., Chisholm, W. N., and McGinley, W. K. (1957). J. Obstet. Gynaec. Brit. Emp., 64, 255.

Fraser, J. L., and Watt, H. J. (1964). Amer. J. Obstet. Gynec., 89, 532. Gatenby, P. B. B. (1960). Lancet, 2, 1004.

and Lillie, E. W. (1960). Brit. med. J., 2, 1111.

Giles, C., (1960). Lancet 2, 1063.

and Brown, J. A. H. (1962). Brit. med. J., 2, 10.

and Burton, H. (1960). Ibid., 2, 636.

- and Shuttleworth, E. M. (1958). Lancet, 2, 1341.

Girdwood, R. H. (1956). Quart. J. Med., 25, 87

Herbert, V., (1964). Proc. roy. Soc. Med., 57, 377

_, Larrabee, A. R., and Buchanan, J. M. (1962). J. clin. Invest., 41, 1134.

and Zalusky, R. (1962). Ibid., 41, 1263.

Hibbard, B. M., and Hibbard, E. D. (1963). Brit. med. J., 2, 1430.

Hutner, S. H., Bach, M. K., and Ross, G. I. M. (1956). J. Protozool., 3, 101.

Kohler, H. G., Meynell, M. J., and Cooke, W. T. (1960). Brit. med. J., $1,779$.

Lowenstein, L., Brunton, L., Cooper, B. A., Milad, A. A., and Hsieh, Y. S. (1963). Proc. 9th Congr. europ. Soc. Haemat., 364.

-, Pick, C., and Philpott, N. (1955). Amer. J. Obstet. Gynec., 70, 1309.

MacKenzie, A., and Abbott, J. (1960). Brit. med. J., 2, 1114.

Pritchard, J. A., (1962). Amer. J. Obstet. Gynec., 83, 1004.

Ramsay, W. N. M. (1953). Biochem. J., 53, 227.

- (1954). Ibid., 57, 17P.

Roberts, J. A. F. (1959). Brit. med. Bull., 15, 129.

Scott, J. M. (1957). Brit. med. J., 2, 270.

(1961). J. Amer. med. Wom. Ass., 16, 132.

(1962). Postgrad. med. J., 38, 202.

Segerdahl, E. (1941). Acta med. scand., 108, 483.

Waters, A. H., and Mollin, D. L. (1961). J. clin. Path., 14, 335. 